\title{
DOLORES MEDIO EN LA NOVELA ESPAÑOLA DEL MEDIO SIGLO. EL DISCURSO DE SU NARRATIVA SOCIAL
}

Lucía Montejo Gurruchaga

UNED. Madrid

\section{RESUMEN}

En este artículo se analizan las obras de Dolores Medio que se ajustan a los principios de la novela realista y que aportan una mirada uniforme dentro de la tradición testimonial de la época. Desde la publicación de su primera novela Nosotros, los Rivero (1952) y más aún en Diario de una maestra (1961), adopta una postura política e ideológica, y con una actitud crítica y de denuncia relata la situación política y social que un amplio sector de la población padece en la España de pre y posguerra.

Se hacen públicos por primera vez los expedientes de censura de sus obras, y se demuestra que a través de la tendencia realista encontró el cauce de expresión de una sensibilidad literaria, política e ideológica.

Dolores Medio nace en Oviedo en 1914 y muere en 1996. Recibe el Premio de cuentos Concha Espina por Nina en 1945 convocado por el Diario Madrid, al que sólo podían concurrir mujeres, y el Nadal en 1952 con Nosotros. los Rivero; a partir de esa fecha alternará ininterrumpidamente la publicación 
de novelas y cuentos con profusión y dedicación tenaz ${ }^{1}$. Sus novelas, ceñidas casi siempre a los estrechos límites culturales y lingüísticos y al lenguaje sobrio y sencillo de la narrativa de posguerra, aportan una mirada uniforme dentro de la tradición testimonial de la época. Durante dos décadas asume los principios de la tendencia realista; sus obras se encaminan sucesivamente hacia la observación directa y ganan en objetividad. Sus novelas, salvo excepciones, no se han reeditado ${ }^{2}$; la mayoría son hoy muy difíciles de encontrar.

Pero esto no ocurre sólo con Dolores Medio. Hay un nutrido número de mujeres escritoras que publican en las décadas cincuenta y sesenta, adscritas muchas de ellas a la llamada corriente social, que - como ella- se incorporan tarde a la carrera literaria, y que - también como ella - han quedado relegadas al olvido. Si bien es cierto que algunas - Carmen Laforet, Ana María Matute, Carmen Martín Gaite, Elena Quiroga, Mercedes Soriano- tienen una amplia bibliografía después de una larga y fecunda trayectoria literaria, hay otras muchas - Concha Alós, Mercedes Ballesteros, Teresa Barbero, Rosa María Cajal, Paulina Crusat, María Jesús Echevarría, Mercedes Fórmica, Luisa Forrellad, Carmen García Bellver, Carmen Kurtz, Susana March, Liberata Masoliver, Eva Martínez Carmona, Mercedes Sáenz Alonso, Ángeles Villarta- cuyas obras apenas se han reeditado en las últimas décadas y sus nombres se siguen omitiendo o son una mera referencia en las nuevos estudios sobre la narrativa de ese periodo.

La primera obra de Dolores Medio, Nosotros, los Rivero, con la que ganó en 1952 el Premio Nadal ${ }^{3}$, y algunos de sus primeros relatos, están dentro de

1 A su primera novela le seguirán, en corto tiempo, estas otras: Funcionario público (Barcelona, Destino, 1956), El pez sigue flotando (Barcelona, Destino, 1959), Diario de una maestra (Barcelona, Destino, 1961), Bibiana (Madrid, Bullón, 1963), El señor García (Madrid, Alfaguara, 1966), La otra circunstancia (Barcelona, Destino, 1972), Farsa de verano (Madrid, Col. Austral, EspasaCalpe, 1973), El fabuloso imperio de Juan sin Tierra. Barcelona, Plaza\&Janés, 1981), y algunas colecciones de cuentos como Andrés. Premio Sésamo de Cuentos (Oviedo, Richard Grandío, 1967), El Bachancho (Madrid, Magisterio Español, 1974), El Urogallo (Oviedo, Onega, 1982), La última Xana (Oviedo, Fundación Dolores Medio, 1986) y sus libros de memorias Atrapados en la ratonera. Memorias de una novelista (Madrid, Alce, 1980) y En el viejo desván (Memorias), (Oviedo, Caja de Ahorros, 1991). Su último libro es una recopilación de relatos y poemas —de años diversos-que con el título Moriré sola (Oviedo, KRK, 1998) se publicó a los dos años de su muerte.

2 Es el caso de Diario de una maestra, edición, introducción y notas de COVADONGA LOPEZ. Alonso, Madrid, Castalia, 1993.

${ }^{3}$ Dolores Medio, Nosotros, los Rivero, Barcelona, Destino, 1953. Fue tal el éxito de lectores que sólo un mes después de la primera edición se hizo la segunda. En 1955, Destino ponía a la venta la sexta. La crítica no la acogió de forma unánime. ANTONIO VILANOVA decía: «el profundo poder de evocación y evidente intuición humana revelan en su autora unas indiscutibles dotes narrativas y una limpia sensibilidad creadora» (Destino. 821, 2 de mayo 1953, 21). EMILIO GoNZÁLEZ LÓPEZ la incluyo dentro del conjunto de obras que auguraban «un renacimiento del arte novelesco 
los cauces del realismo tradicional, de corte decimonónico, con tintes costumbristas. No evita la realidad concreta políticosocial en la que la trama se desarrolla. La narración, sencilla y lineal, de lenguaje coloquial y funcional salpicado de frases hechas, formas populares y vocablos de sabor dialectal de su primera novela, arranca en la primavera de 1950, el día que Lena Rivero-después de años de ausencia- vuelve a la ciudad de Oviedo. Se ha convertido en escritora y en el paseo que la lleva de la estación al hotel rememora los lugares, personas y acontecimientos de su infancia y adolescencia ocurridos durante el decenio 1924-34, de violencia y represión policial: el padre, el Aguilucho, que hizo fortuna en Cuba y a su vuelta ha puesto una gran bodega; la señora Rivero, siempre pendiente de lo que dirán los otros; Magda, la tía soltera que se encarga de que la casa marche; Heidi, la hija que el Aguilucho trajo de Cuba; Ger, el hermano revolucionario; María, siempre rezando y que morirá en las misiones, y Lena, la pequeña, rebelde, dispuesta siempre a ser una chica distinta a las señoritas de su tiempo y en la que la autora vierte muchos rasgos de su autobiografía.

Un narrador omnisciente, que posee toda la información, percibe la totalidad del mundo novelesco, sabe todo lo que incumbe y rodea a los personajes y como un demiurgo coloca al lector en posición de conocer todos sus secretos, e incluso se adelanta a contar hechos antes de que ocurran, introduce al lector en el estrecho círculo familiar de los Rivero, en el ambiente y en la vida provinciana de la ciudad, en el marco social, económico y político en el que se mueven sus personajes. Las detalladas argumentaciones sobre los cambios políticos del periodo - Dictadura, República, Octubre rojo-, la participación en ellos de Ger, la peculiar idiosincrasia y los rasgos liberales de algunos de sus miembros, van a ocasionar problemas a la autora con la censura; será su primer encontronazo, pero no será el último.

Dolores Medio tuvo frecuentes altercados con la censura española y desde el principio de su producción. Sufrió su acoso desde 1952 algo que contradice lo que muchas veces se ha dicho: que los censores eran más benévolos con los autores menos significados y más aún si eran autoras.

español» (Revista Hispánica Moderna, Nueva York, XXI, 1955, 150). Por el contrario, MelchoR FERNÁndez ALMAGRo señalaba que en el futuro debería trabajar «para preservarse contra la tentación del tópico» $(A B C, 10-\mathrm{V}-53)$ y JUAN LuIS ALBORG repetía -en una relectura ocho años después de su publicación: Nosotros, los Rivero «se nos ofrece incuestionablemente como un libro muy mediocre que no está llamado a tener ninguna significación». (Hora actual de la novela española II, Madrid, Taurus, 1962, 335). El lector encontrará un análisis exhaustivo de esta novela - la sociedad ovetense, la vida comercial, aspectos urbanísticos de la ciudad, el tiempo, los personajes- en CARMEn Ruiz ARIAS: La obra literaria de Dolores Medio. Tesis doctoral, Universidad de Oviedo, 1990. 
Nosotros, los Rivero ${ }^{4}$ se presentó en censura, como era preceptivo, para recibir la tarjeta de autorización para su publicación, el 11 de febrero de 1952. Se le asignó el número de expediente 668-52 y está archivado en el AGA (Archivo General de la Administración de Alcalá de Henares) ${ }^{5}$. Un censor escribe el día 22 -M. Batanero- sobre la solicitud y con lápiz rojo la palabra: Suspendido. El lector núm. $13^{6}$ propone la Suspensión con el siguiente informe:

« ¿Ataca a la moral? Sí.

¿Al Régimen y sus Instituciones? Sí. Págs. 115, 116, 302, 312, 314, 318, 320, 322, 367, 307 sigs. 381, 390, 393, 398, 405, 430, 473 sigs., 483, 492, 497, sigs. 521, 524, 527, 542 .

RESULTANDO: «La autora de esta novela demuestra su simpatía por la República española del 14 de abril y su antipatía por las tropas españolas que pacificaron Asturias en 1934. En cuanto a la moral es a veces cruda en descripciones y perniciosa en teorías. Tiene un capítulo en que un hermano habla a su hermana de modo tan cínico y desvergonzado que resulta repugnante aunque lo haga con la piadosa intención de aleccionarla en la vida. Hay elogios de obras comunistas, de Stalin, etc. Es completamente reprobable. Los capítulos de seudomisticismo de la protagonista son irreverentes y desagradables.»

El 25 de febrero de 1952, la editorial recibe la resolución. Se le comunica que la Dirección General de Propaganda, a propuesta de la Sección correspondiente, ha resuelto DENEGAR la autorización necesaria para la publicación de dicha obra.

4 Era la novena convocatoria del Premio Nadal que había conseguido prestigio en el mundo literario. Aquel año se presentaron 107 originales y el jurado había estado compuesto por: Ignacio Agustí, Juan Teixidor, José Vergés, Juan Ramón Masoliver, Néstor Luján, Sebastián Juan Arbó y Rafael Vázquez-Zamora. Para una información detallada del fallo y demás circunstancias que rodearon la concesión del premio puede verse: José MARÍa Martínez CaChero, «Dolores Medio, noveno premio «Nadal» (1952)», Archivum, Homenaje a la memoria de José María Roca Franquesa, XXXIV-XXXV (1984-1985) 55-67.

${ }^{5}$ Este expediente y los que daré a conocer después, es la primera vez que se hacen públicos. Durante cincuenta años han permanecido en el Archivo. No falta ninguno; tanto los que corresponden a las primeras ediciones como a las posteriores tenían que recibir la tarjeta de autorización. El último expediente abierto a una obra de Dolores Medio corresponde a El fabuloso imperio de Juan sin Tierra; es el núm. 7735/81 y lo solicitó Plaza y Janés el 20-7-81, lo que demuestra que a pesar de que la transición política había concluido, se había instaurada un régimen democrático y se había abolido en 1977 este órgano de control, los editores seguían solicitando el permiso, y lo que es más inaudito, recibiendo la tarjeta de autorización.

${ }^{6}$ Los censores - -lectores en el argot de la Dirección General de Propaganda del Ministerio de Educación Nacional - estaban organizados por categorías que iban desde el jefe de lectorado, el lector especialista, el eclesiástico, lector fijo y eventual. Había personas de prestigio, catedráticos, y otros cargos cercanos al régimen franquista, y personas de escasa formación cultural. Se identificaban por un número y estampaban una firma ilegible al final de los informes. 
Dolores Medio no se resigna a aceptar humildemente el resultado y, aunque no era habitual ya que las ordenanzas lo prohibían ${ }^{7}$, dirige al Ilmo. Sr. Director de Información una carta, que está archivada junto al expediente, en la que se defiende de los ataques de crudeza en las descripciones de su novela alegando «que habiendo cursado estudios de Psicopatología en la Escuela Superior de Educación, siendo alumna del doctor Vallejo Nájera, concibió el proyecto de recoger en una novela la vida de unos muchachos anormales (concretamente: psicópatas pasionales) cuyas reacciones estudió minuciosamente, a fin de que la novela fuese lo más realista y científica posible. Que va engarzada en la trama de una antigua y piadosa leyenda asturiana, que asegura que nadie podrá disfrutar plenamente de los bienes arrebatados a la Iglesia. Que está ambientada en el Oviedo del primer cuarto de siglo, habiéndose documentado la autora, para su desarrollo y lenguaje apropiado, en los periódicos locales de la época». Concluye diciendo «que si ha incurrido en alguna falta ha sido involuntariamente y suprimirá con mucho gusto cualquier párrafo o concepto que la censura considere inconveniente» y solicita «a V.I. se digne señalarle los errores en que haya podido incurrir para poder rectificarlos, de modo que pueda autorizarse la publicación de dicha novela».

Empieza entonces un forcejeo entre los censores. La novela pasa por distintas manos, práctica común cuando se trataba de un libro calificado de peligroso, y van emitiendo sus informes, que están archivados en el expediente. Uno de ellos, V. García Yebra, señala el 14 de marzo de 1953 que «la novela no ofrece reparos graves desde el punto de vista religioso ni desde el moral. El punto más discutible es el político. La protagonista se inclina más bien hacia la izquierda; durante un periodo de su vida participa incluso activamente en la política socialista, y en todo momento muestra gran admiración por su hermano, que muere en la revolución de octubre del 34, en Asturias, luchando contra las fuerzas del Gobiemo. En todo momento manifiesta más simpatía por las ideas revolucionarias que por las conservadoras. Por otra parte, su figura resulta empequeñecida cada vez que se compara, especialmente hacia el final de la obra, en las páginas decisivas, con la de su hermana María, muchacha extraordinariamente piadosa, que acaba haciéndose misionera y sufriendo el martirio en Filipinas. Termina diciendo que la obra no puede extraviar políticamente a nadie, y que, por tratarse de una novela de notable mérito literario, se podría tener con ella al-

7 Conviene recordar que una de las reglas recogidas en las Instrucciones que debían seguir autores y editores, la número ocho, decía textualmente: «Toda instancia vendrá dirigida al Director General de Propaganda y nunca a nombre de ningún funcionario del Servicio. Las cartas particulares sobre publicación de obras enviadas a los funcionarios no serán contestadas, dándose por no recibidas.» 
guna mayor benevolencia y autorizarla, aunque convendría suprimir los pasajes tachados en las páginas 96, 118, 115 y 120.» Al final de este informe alguien que no firma, escribe cuatro días después las siguientes frases: «Vistos antecedentes, denegatorios, y el informe anterior, a lectura en nuevo historial interesando concrete su pertinencia desde el punto de vista político.» El lector $\mathbf{n} .^{\circ} 1$-Condeobserva: «es una novela bien construida desde el punto de vista literario y temático. Hay tres personajes que forman el cañamazo de la obra y que viven toda la emoción novelística: Lena Rivero, su hermana María y Germán, el hermano. Lena, es una muchacha inquieta que simpatiza con ideales poco ortodoxos en ética social y política —estamos conformes con las tachaduras del Censor anterior- y refiere su vida y de sus familiares durante varias décadas. María, es la muchacha fiel a la conciencia religiosa que ofrece su futuro misional por la salvación de su hermano. Germán, incorporado a las ideas socialistas, aplaude la llegada de la revolución social, vive activamente el octubre rojo del 34 en la Capital asturiana y muere en el asalto a Oviedo. Se hacen dos tachaduras (páginas 114 y 115) que estimamos como excesivo lirismo republicano y revolucionario. La obra puede autorizarse con las tachaduras antes y ahora señaladas ${ }^{8}$. Sobre es-

* Copio los informes tal y como figuran en el documento original, sin añadir ni quitar una coma. Voy a señalar las tachaduras en la que coinciden los censores para que el lector se haga una idea clara de lo que este órgano perseguía con especial ahínco. El segundo párafo del capítulo XX aparece así en el manuscrito que acompaña al expediente: «Decididamente, la habitación de Ger no era ya su deliciosa torre de marfil, en la que podía aislarse del resto del mundo, No obstante, su interior conservaba el mismo aspecto de rebeldía y desorden que siempre había caracterizado a sus dominios. Rabindranath Tagore continuaba disfrutando su puesto de preferencia sobre las paredes, pero Charito de Triana, aquella bailarina del «Suizo» que, según contaba Heidi, era amiga de Ger. había sido desbancada por la efigie de Mariana Pineda, a la que custodiaban, dando guardia de honor, los retratos de Galán y García Hernández, y la bandera republicana, que ni una ni otros habian visto ondear. Sobre la bandera habia clavado Ger, como una reliquia, una hoja de calendario, señalando una fecha: 14 de abril de 1931." Las frases que aparecen subrayadas son las que hubo que suprimir para siempre. Las alusiones a un militar republicano que tomó parte en los acontecimientos de la noche de San Juan de 1926 contra Primo de Rivera, fue encarcelado y más tarde amnistiado. y junto al capitán García Hernández participó en la sublevación antimonárquica de 1930 en Jaca, siendo sometidos a consejo de guerra, condenados y ejecutados, y a la fecha de la proclamación de la Segunda República Española, no pasaron desapercibidas a los censores. La segunda supresión corresponde al párrafo siguiente y son las líneas subrayadas: "Había periódicos y revistas por todas partes: sobre la mesa, sobre el pupitre de hule negro, que había servido de escritorio al "Aguilucho", sobre la estantería, sobre la estufa (ahora siempre apagada). A Lena le resultaban familiares sus títulos, destacados en las recientes ediciones, que aún olian a tinta fresca: El Plan Quinquenal, de Stalin; Técnica del golpe de Estado, de Malaparte; La rebelión de las masas, de Ortega y Gasset; Historia de la Revolución Rusa, de Trotski; Los creadores de una nueva Europa, de Sforza; La joven India. de Gandhi; Europa y el fascismo, de Heller; Bela Kun y el comunismo húngaro, de Révesz; La transformación social de Rusia, de Máximo Gorki; Comunismo, de Lasky; La mujer en el pasado, en el presente y en el porvenir, de Bebel; Socialismo constructivo, de Mann; Testamento político, de Engels... Libros, libros, libros". Todos estos títulos aparecen atravesados por dos grandes aspas rojas. 
te último informe y con fecha 20-4-53 alguien escribe las siguientes palabras: «Efectuadas las tachaduras señaladas. Conforme.» Dos días más tarde se expende la tarjeta de autorización.

La supresión de estos párrafos descarga a la novela de componentes ideológicos decisivos, la aleja de una determinada tradición ideológica-cultural, y su ausencia deja sin explicación algunos comportamientos posteriores; sin ellos, el carácter de algunos de los personajes, su proceder y sus resoluciones resultan incoherentes. Algo más de un año tardó en resolverse la querella y pudo ser publicado con tachaduras, supresiones y enmiendas, en abril de 1953.

Tres años más tarde Dolores Medio publica Funcionario público ${ }^{9}$, la primera obra escrita por una mujer que se ajusta a los procedimientos teóricos de la novela realista. Un narrador objetivo en tercera persona, que crea la ilusión de la objetividad, incluyendo, entre otras fórmulas, retazos de artículos de los periódicos de la época, narra la vida de Pablo Marín. Este funcionario de Correos, pendiente de un mísero sueldo fijo del presupuesto del Estado, está casado con Teresa y viven estrechamente en un cuartucho. Marín hace castillos en el aire sobre posibles subsidios y subidas de sueldo que les permita salir de tanta miseria; sus agobios económicos le privan de la menor aventura emocional que le compense del amor perdido de su mujer. Teresa, hundida en el tedio y la rutina, también fantasea con los tiempos en los que podría haber conseguido un marido mejor. Pero los cosas empeoran. Tienen que abandonar la habitación y recorren medio Madrid en busca de otra que - con la carestía de los años 50- no pueden pagar. Se instalan, al fin, en otra igual de mísera y al volver Marín un día del trabajo ve que su mujer le ha abandonado. Se desespera, pero poco a poco, volverá a la rutina.

El tema de la novela no tiene nada de original, incide en la realidad concreta de la España de los cincuenta, en un problema que afecta a una gran parte de la sociedad, - la carestía de la vida y de la vivienda, en particular-. Uno de los aciertos de Funcionario público radica en que esta vida vulgar se convierte en el eje del relato. El manuscrito no tuvo el menor inconveniente cuando se presentó en censura para conseguir la tarjeta de autorización ${ }^{10}$.

El tiempo de la diégesis se circunscribe a unos pocos meses entre el final del otoño y el inicio de la primavera. Los personajes se limitan a estar; mania-

9 Medio, Dolores: Funcionario público, Barcelona. Destino, 1956.

10 El expediente de Funcionario público es el núm. 4430-56. Se solicita la autorización el 20 9-56 y ocho días más tarde un lector emite el siguiente informe: «Novela ambientada en Madrid. época actual donde se pretende reflejar la vida mediocre de un funcionario de Telecomunicaciones que tiene que luchar diariamente para atender a los gastos familiares, y dentro de ello se enlaza un breve suceso de interés femenino hacia una desconocida persona». Se autoriza sin contratiempos. Posteriormente se ha traducido al ruso, al alemán, al rumano. 
tados por la pasividad, viven un proceso de desilusión y escepticismo. Padecen y son víctimas de unas circunstancias. La enunciación de los pensamientos, ideas, preocupaciones de los personajes, los que no comunican a los demás y tienen en ocasiones un tono irónico, amargo y mordaz, los expresa el narrador en un monólogo -que refleja el proceso mental de la conciencia individualque gráficamente aparece entre paréntesis.

Dolores Medio continúa en su afán de dar testimonio objetivo con El pez sigue flotando" . La estructura de la novela ha cambiado: el protagonista individual deja paso al colectivo. Lena Rivero, la protagonista de Nosotros, los Rivero, uno de los personajes femeninos más libres que refleja la novela española de posguerra y que rompe con el discurso mítico del realismo social, reaparece y es el hilo conductor de este relato. De nuevo, un narrador objetivo en tercera persona presenta al lector las vidas de un grupo de personas que viven en el mismo bloque de pisos en el barrio de Chamberí en Madrid. Como en la novela anterior, las reflexiones de los personajes, las que no tienen intención de compartir, aparecen entre paréntesis. Sin embargo, a diferencia de Funcionario público, los juicios irónicos, mordaces, aparecen en cursiva. Este grupo social - clase media baja- que acepta un sistema de valores que no cuestiona, está formado, entre otros, por: Senén Morales, el mercero; Marta Ribé, burguesa venida a menos, que malvive con pequeños trabajos; José Cilleiro, el mísero portero de la casa; Veva Martínez, bailarina; Miren y Víctor Senosiaín, una pareja joven; Tía Romana, una anciana acomodada y atendida por una sobrina que le saca el dinero; Bruno Jiménez, que vende juguetes por las calles; Juana Galán, que recorre Madrid en busca de trabajo.

La reducción espacio-temporal -la diégesis se resuelve en unos meses de mediados de la década de los cincuenta-, la presentación simultánea de distintas realidades individuales — personas de ambos sexos-y las relaciones que mantienen, aportan la visión de un determinado grupo social cuya característica común es la miseria moral y económica en muchos de ellos. Cada capítulo tiene como protagonista a uno o varios de estos personajes y mediante una narración fragmentada llevada de la mano de la objetividad de un narrador en tercera persona y la subjetividad que introducen los personajes en el diálogo y

1 Medio, Dolores: El pez sigue flotando, Barcelona, Destino, 1959. Se presentó en censura con el título de El acuario. Se trata del expte. Núm. 5416-58; el censor informa de que «es una novela en la que se describe la vida de una casa de inquilinos, en cuadros aislados, sin mucha relación entre sí, una escritora, un portero, una muchacha que trabaja, una bailarina, un matrimonio joven, etc. La autora presenta la vida de cada uno de estos personajes, intentando unirlos con el sutil hilo de la vida en general». El manuscrito fue autorizado con una tachadura: el censor consideró que incluía un ataque a la Iglesia y a sus Ministros, porque uno de los personajes les achacaba la culpa de algunos de los males del país, en especial, de la sequía. El fragmento fue suprimido. 
en los fragmentos entre paréntesis — la voz de la individualidad-, se produce un equilibrio entre la realidad exterior y la interior que es posiblemente la técnica más lograda a lo largo de la novela. Con la inserción de ciertos elementos metafictivos -recordemos que Lena Rivero es escritora y se cuestiona sobre la dificultad de hallar un tema, de combinar los «materiales» con los que creará la obra-, el uso de firmas internas — como la alusión a personajes de su primera novela-, la inclusión de textos de carácter científico, histórico y hasta fragmentos de una novela rosa que Marta Ribé, la mecanógrafa, copia sin sosiego para ganarse la vida, la autora enlaza la ficción con la sociedad en la que ha sido creada. Dolores Medio ha abandonado la evocación, la fácil evasión sentimental de su primera novela en busca de tipos y temas concretos, del testimonio y la denuncia de una realidad concreta y de unas determinadas circunstancias históricas ${ }^{12}$. Decía de sus novelas «que sin pretensiones de hacer historia narran el pequeño vivir de unos personajes que se mueven dentro de un ambiente determinado y de una determinada época, son una página para la Historia. Del estudio de todas ellas podrá deducirse algún día la forma de vivir de nuestro país durante la época actual» ${ }^{13}$.

Dos años más tarde Dolores Medio publica Diario de una maestra ${ }^{14}$. Es una novela social en el más estricto sentido del término, en la que sin tapujos ni medias tintas, la autora adopta una postura política e ideológica y con actitud crítica y de denuncia relata la situación política y social, que un amplio sector de la población padece en la España de pre y posguerra.

En su línea de literatura como vida, con un deber moral y como tesis a la razón histórica, sigue utilizando los mismos procedimientos técnicos de raigambre tradicional y conservadora. Este diario recoge quince años de recuerdos: 28 capítulos que van desde el 18 de mayo de 1935, al 4 de mayo de 1950. $\mathrm{El}$ diario que, por su propia naturaleza, es la expresión de uno mismo, de su

12 G. DE NoRa, Eugenio: La novela española contemporánea (1939-1967), III, Madrid, Gredos, 1970, 166. Para NoRA, si «Nosotros, los Rivero no era sino la primera tentativa seria de una joven maestra nacional, provinciana y prácticamente autodidacta, las dos nuevas novelas aparecidas después (Funcionario público en 1956, y El pez sigue flotando en 1959) acreditan inequívocamente a Dolores Medio como narradora excepcional».

${ }^{13}$ MEDIO, DOLORES: «Comentarios en tomo a la novela social», Cuadernos para el diálogo, núm. 29, 29.

${ }^{14}$ Medio, Dolores: Diario de una maestra, Barcelona, Destino, 1961. La autora ejerció el magisterio desde 1932 en el sistema de enseñanza fomentado durante la República. Fue expedientada durante la guerra civil por la Inspección Provincial de Enseñanza aunque se reincorpora a su escuela en Asturias en 1940. Abandonará la profesión a raíz de la concesión del Premio Nadal y se instalará definitivamente en Madrid para dedicarse exclusivamente a la creación. Para una información detallada sobre estos y otros datos biográficos véase Atrapados en la ratonera. Memorias de una novelista (op.cit.). 
identidad psíquica, la revelación de la privacidad de la conciencia, recoge la vida de Irene Gal, pero no en primera persona, como era de esperar, sino con la distorsión de un narrador en tercera. Irene acaba de terminar sus estudios de Magisterio y recibe el curso preparatorio antes de tomar el destino como maestra. Corre el año 1935 y tiene diecinueve años. Ahí conoce al profesor Máximo Sáenz, con quien mantiene una impetuosa relación amorosa. La destinan a una aldea asturiana y empieza su difícil tarea como maestra. Su ideología republicana, su enseñanza innovadora, sus ideales de renovación y libertad chocan con las ideas conservadoras de los paisanos, con la mezquina y roma vida rural. Su carácter inconformista, rebelde, su entusiasmo y su entrega son calificados de heterodoxos. Estalla la guerra civil y Max es encarcelado por su ideología socialista. Ayuda como enfermera en el hospital y allí se entera de que Max ha sido condenado a muerte. Vuelve a la escuela de La Estrada, pero tiene que pasar por la Comisión Depuradora y es destituida temporalmente. Subsiste durante unos años con graves dificultades y le espera ayudándole con grandes sacrificios. Vuelve como maestra al mismo lugar. Recobra su entusiasmo por la escuela y el pueblo y doce años después Max sale de la cárcel. Se rencuentran pero él es otro hombre; la cárcel ha terminado con sus ideales y va a casarse con una mujer rica.

La anécdota amorosa invade todo el relato y limita la trascendencia de los conflictos sociales y políticos que la novela relata. La censura digería mejor una obra en la que resaltaran - al menos a primera vista- grandes pasiones y conflictos dramáticos, que la expresión abierta de ciertas discrepancias en asuntos sociales y políticos. Pero en aquellos momentos y con la ya larga experiencia censora que Dolores Medio tenía, no era fácil resolver con éxito el compromiso moral e histórico, el sentido ético en el que había empeñado su labor narrativa.

Un manuscrito de estas características no podía pasar indemne el trámite de la censura. La editorial Destino presentó el manuscrito el 14 de octubre de $1960^{15}$. El censor observa que la obra está «enmarcada en los acontecimientos que ofrece la vida española entre los años 1935 y 1950, Dolores Medio traza el perfil humano y profesional de una Maestra rural, de Irene Gal, convertida en protagonista y centro de su novela, a la que titula Diario de una maestra. Con alusiones a técnicas educativas que pretenden tener sabor de

${ }^{15}$ El papel que jugaron los editores está aún por estudiar. Si bien es cierto que en sus manos recayó todo el peso cultural que el Estado no asumía, no es menos cierto que solían expurgar de antemano lo que juzgaban censurable o sujeto a dudas y practicaban, en ocasiones, una censura previa a la oficial. El editor solicita el permiso para imprimir una tirada de 3.000 ejemplares y se le asigna el número de expediente 5465-60. Copio los informes tal y como figuran en el original. 
modernidad, parece querer mostrar el poder y la eficacia de la educación metódica y adaptada a cada particular psicología y condición. Tal es, por ejemplo, el caso de Timoteo, el muchacho procaz y blasfemo que, como fruto de su obra, supo morir a manos de los rojos por defender al cura del pueblo donde ella ejercía. Al lado de esto, no deja de ser absurda y compleja la particular contextura de la joven Maestra, entre ingenua y desvergonzada en sus relaciones con un Profesor de Universidad, a cuyo recuerdo heróicamente se consagra. La novela está demasiado atenida a la dimensión humana, terrenal de las cosas. La falta proyección hacia lo alto, sentido e intención de trascendencia, precisamente en la vida y en la obra de una Maestra, española y cristiana, que debe conocer y servir al fin supremo de toda educación cristianamente entendida. Ello no obstante, puede autorizarse, con las siguientes tachaduras señaladas en las páginas $8,9,13,20,21,31,32,33,36,37,58,59$, $62,94,95,111,112,122,126,127,128,133,135,139 . »$

El 28 de octubre se le comunica a Destino que se autoriza con las supresiones señaladas y que se les concederá la tarjeta en cuanto remitan la nueva galerada impresa con las supresiones exigidas, lo que cumplen con fecha 16 de diciembre de $1960^{16}$. Cuatro días más tarde se les remite la tarjeta de autorización. El editor entrega el 4 de marzo los ejemplares de depósito y ratifica que son de idénticas características al manuscrito original autorizado.

Tres años más tarde de llevarse a cabo la primera edición mutilada, el 20 de julio de 1963, Dolores Medio «interpone RECURSO DE REPOSICIÓN»; dirige una carta al Ilustrísimo Señor Director de Información y Turismo «para demandar la revisión de la citada novela, teniendo en cuenta que cuanto en ella se ha suprimido nada tiene de ofensivo para la Religión ni para la Patria y se ha suprimido, únicamente, por supuestas razones morales». Añade que «para la moral no existen, al parecer cánones a los que debamos ajustarnos estricta-

${ }^{16}$ Los párrafos y fragmentos suprimidos los señala en algunas notas Covadonga LóPEZ Alonso en la edición de Diario de una maestra ya citada. Ha cotejado las tres ediciones (1961, 1984 y 1985), ha marcado los fragmentos mutilados y ya repuestos en la edición de 1984 . Se comprueba fácilmente que las líneas censuradas se refieren a escenas amorosas, algunas de cierto erotismo, o a la evocación de las mismas. Estas mutilaciones desvirtúan la calidad de las relaciones entre los protagonistas. Esto demuestra que la mayoría de los censores estaban especialmente entrenados para detectar comportamientos que pronto tildan de inmorales $y$, por el contrario, podían emitir juicios más benévolos sobre asuntos que, vistos con más detenimiento, resultaban ataques a la ideología imperante y al régimen instituido. Resulta sorprendente que no llamaran la atención del censor la ruptura y transgresión de mitos fundamentales de la España de posguerra. No sufrieron mutilaciones párrafos en los que se abogaba por el trabajo de la mujer fuera del hogar, se defendía una enseñanza laica, liberal e igualitaria, se denunciaba la penosa situación de los presos políticos tras la victoria del régimen franquista, y se apoyaba la orientación ideológica de la España de la República. 
mente, o por lo menos esas medidas no se aplican por igual a todos los novelistas, posiblemente por tratarse de diferentes censores y por tanto de diferentes criterios o apreciaciones sobre la moral, ya que, palabras, frases, pensamientos y situaciones suprimidas en Diario de una maestra, se encuentran en otras novelas publicadas recientemente y dichas de una manera más cruda y hasta más grosera», apuntando, además, que «puede aportar pruebas que permitan un estudio comparado, si la censura lo desea». Cree, asimismo, «que lo suprimido son palabras, párrafos, soliloquios, que la autora supone de importancia vital para la comprensión de la novela». Añade, «que aguarda esta justa revisión para autorizar la publicación de la segunda parte de la novela, en España» y «que una novela publicada en el extranjero por incompatibilidad con la censura española, es perjudicial para el buen nombre de España y obliga a la autora a cometer un acto antipatriótico». Termina diciendo que «la autora de la novela quiere y debe velar por la integridad de su obra, sabiendo, en conciencia, que nada se dice en ella que otros novelistas no expresen con mayor libertad» y por este motivo, «SUPLICA a V.I., se digne revisar la citada novela y autorizar la publicación íntegra de la misma».

El 1 de agosto de 1963 - los censores también trabajaban en pleno verano- el lector núm. 26, F. Aguirre, que firma con todas las letras, emite un informe en el que después de reseñar el argumento dice: «la protagonista es inmoral en su vida privada y parece carecer de ideales religiosos, hay escenas escabrosas muy subidas pero se trata de una obra para.personas ya mayores por su extensión y argumento». Añade que «esta obra no pasaría hace años pero yo creo que según el criterio actual de esta censura se puede permitir su publicación» ${ }^{17}$. El 3 de agosto Dolores Medio recibe contestación a su Recurso de Reposición. Se le comunica «que esta Dirección General accede a la publicación del texto íntegro presentado en esta Sección con fecha 20-10-60.»

Unas semanas antes la censura ha autorizado la publicación de Bibiana, otro relato menor del vivir cotidiano en la España de la posguerra, con la que

${ }^{17}$ Esta carta está archivada en el AGA junto al expediente correspondiente. Es posiblemente una de las cartas más valientes - y he visto muchas en los años que he trabajado en el AGAdirigidas al órgano censor. En los primeros años de la dictadura franquista los principios que regían esta institución se cumplieron con severidad, y siempre arbitrariamente. Con la llegada de Fraga Iribarne, que ocupó el Ministerio de Información y Turismo desde 1962 hasta 1969, sus efectos fueron menos dañinos, ya que sus normas se aplicaron con un cierto grado de tolerancia. Dolores Medio utiliza en esta carta unos argumentos de los que no hay la menor noticia. Me pongo en contacto con la Fundación Dolores Medio y su portavoz, Víctor Alperi -periodista, ensayista y escritor de larga, variada y fecunda trayectoria narrativa - me confirma que nunca llevó a cabo, ni hay indicios entre sus papeles en la Fundación, de que la autora pretendiera publicar una segunda parte del Diario. Me corrobora, asimismo, que nunca se publicó fuera de España. Se trata de estrategias de las que los autores se servían para apoyar y facilitar la aprobación del manuscrito íntegro. 
Dolores Medio inicia la trilogía Los que vamos a pie ${ }^{18}$. La acción transcurre en unos pocos meses, de nuevo en el Madrid de la posguerra y en el barrio de Chamberí. Parece que la autora ha encontrado un registro en el que se siente cómoda y no ve la manera de salir de él. Se repiten los problemas que ya ha planteado en sus novelas anteriores - la carestía, la escasez, la monotonía- de una familia de clase media baja. Bibiana es un ama de casa menesterosa, temerosa, pudorosa, simple en sus planteamientos, amante de su marido y sus hijos y sin vida personal, que representa la estabilidad familiar. Hace milagros con el poco dinero que Marcelo — dueño de una humilde tienda de tejidos- le entrega, y ambos comparten una vida monótona centrada en sus cinco hijos. Un narrador que a veces se muestra objetivo, que se mantiene al margen y parece actuar como mero testigo de los hechos, y otras omnisciente, penetra en la interioridad de los personajes, recoge sus consideraciones, ideas, ilusiones y proyectos; los que no comunican a los que comparten con ellos la diégesis se diseminan como un reiterado y recurrente monólogo interior, tal como ya hiciera en las dos novelas anteriores, entre paréntesis, marcas gráficas dirigidas al lector que le alertan y la advierten para que tome parte. El diálogo es la técnica fundamental de este relato y mediante él avanza una trama que se reduce a aspectos intranscendentes de la vida cotidiana.

Sin embargo, y aunque no como temas relevantes, reaparecen los motivos que han preocupado siempre a la autora asturiana: la injusticia social, la vida de la clase media baja en el ámbito urbano, la mujer víctima de su escasa formación, resignada y sujeta a los designios del marido y arrastrando una vida gris, solitaria y anónima que sólo se justifica en la realización vital de los demás miembros de la familia, la incomunicación. El humor, casi siempre exento de ironía y con significado de interpretación literal, recorre no solo Bibiana sino todas las novelas de la autora. No se trata de un humor sagaz, artificioso, alegórico o paródico, sino de un humor transparente, coloquial, comunicativo, que solo requiere un lector ingenuo y crédulo, y descarta en su intencionalidad la reconstrucción o reinterpretación del discurso dado.

Bibiana es, además, un eslabón más de esas estructuras narrativas que otorgan escasa importancia a la figura masculina; recordemos que en Nosotros, los Rivero, la protagonista es una mujer y su vida se desenvuelve en un mundo casi exclusivamente femenino, protagonista que también guiará el universo colectivo de El pez sigue flotando. En Diario de una maestra la protagonista abre y cierra el relato. Así como en las tres novelas mencionadas la protagonista es una mujer rebelde, activa, que rompe con el mito del recato y busca una independencia económica y social, que presenta alternativas para su integra-

${ }^{18}$ Medio, Dolores: Bibiana, Madrid, Bullón, 1963. 
ción social - como escritora, maestra-, que rompe, por tanto, con los personajes femeninos que representa habitualmente la narrativa de posguerra, en $B i$ biana volvemos a encontrar a una mujer tradicional, envuelta en la rutina, en lo repetitivo, en lo cíclico, que asume la ética del sacrificio.

La autorización para la publicación de Bibiana se cursó el 8 de mayo de $1963^{19}$. El censor observa: «con aire de serial radiofónico se relata la vida ordinaria de una familia compuesta del matrimonio, pequeños industriales, y los cinco hijos. Los problemas caseros, la lucha por la vida difícil, los problemas que originan los hijos, etc. Es, en resumen, de escenas costumbristas de una familia media madrileña. Debe suprimirse la afirmación de la página 313, ya que puede contribuir a dar una visión desfigurada de la justicia de post-guerra, toda vez que por ser oficial del ejército republicano solamente, no se fusiló a nadie ${ }^{20}$ ». Sin embargo, alguien rectifica esta resolución y en un lateral del informe, escribe: «No ha lugar a suprimir lo subrayado en pág. 313. Puede autorizarse ${ }^{21}$ ».

La segunda novela de la trilogía, La otra circunstancia, no se publicará hasta pasados nueve años ${ }^{22}$. La tesis que Medio presenta en esta novela es que el hombre, sea cual sea su condición social o su nivel económico puede fácilmente dejarse arrastrar por las circunstancias. El manuscrito se presentó a censura el 28 de abril de $1972^{23}$ y un lector atento y minucioso informa pocos días después que «es la historia de un hombre - y su familia - que de humilde tendero y a causa de una expropiación indemnizada, se mete en negocios de construcción, se hace rico, pierde la conciencia, la paz, la salud y todo cambia en su vida personal y familiar. Al fin sucumbe su suerte al derribarse una casa de las que construye su empresa». Después de describir el argumento añade que «la novela recoge cir-

${ }^{19}$ Se trata del expediente núm. 2665-63. Está, como todos los demás, en el AGA. Copio el informe tal y como aparece en el original.

${ }^{20}$ Se refiere al texto siguiente: «...cuando hacía nueve días que Teófilo Prats, capitán del Ejército republicano había caído frente al piquete de ejecución, y otros dos Prats, Jaime y Eugenio, estaban en la cárcel aguardando sentencia.»

${ }^{21}$ Los expedientes ponen en evidencia con demasiada frecuencia la falta de respeto y poco crédito con que se trataba el cuerpo de censores; sin ningún miramiento se permitían cambiar los juicios emitidos por sus subordinados.

22 Medio. Dolores: La otra circunstancia. Barcelona, Destino, 1972. El mandato de Sánchez Bella. que ocupó el Ministerio de Información y Turismo desde 1969 a 1973, se caracterizó por el continuismo. Fraga Iribarne, que lo ocupó desde 1962 a 1969, convirtió la censura previa, hasta entonces obligatoria, en voluntaria. Un aspecto beneficioso de la Ley Fraga fue que facilitó la aparición pública de las discrepancias políticas e ideológicas con el gobierno y otros órganos de poder pero, por el contrario, legitimó la represión de la expresión aplicando infinidad de sanciones — secuestros y multas de prensa y libros-y provocando situaciones críticas.

${ }^{23}$ Se trata del expediente número 5217-72. La autorización la solicita Destino para una tirada de 3.000 ejemplares. 
cunstancias, mentalidades, estilos de vida, nuevos conceptos sociales y morales de la nueva sociedad española. Por supuesto que aparecen muchas lacras, se describen actitudes pragmáticas y amorales, pero que son testimonio de lo que se ve en la sociedad actual.» Dice, además, que «la novela está bien conseguida y refleja un fenómeno social que no es, desgraciadamente, ninguna ficción.» Añade que no ofrece problemas su admisión porque «la novela no plantea ni defiende ninguna tesis inmoral. Simplemente describe una miseria social y humana que todos presenciamos y lamentamos: es la prostitución de la dignidad personal en aras de la merma en los negocios. En resumen, que debe admitirse. No hay apología del mal ni descripciones inmorales ni ataques a ningún valor religioso o político." La trama se centra en el ascenso económico y social del protagonista, Marcelo Prats, marido de Bibiana y amante de Lolita.

Dolores Medio muestra en La otra circunstancia el cambio socioeconómico que se produce en la España de los sesenta en la pequeña y mediana burguesía y la decadencia, corrupción y miseria moral que le acarrea. Con los rasgos específicos de la narrativa realista que le son propios —narración en tercera persona, abundancia del diálogo, creación de personajes autónomos-muestra y reflexiona con claridad y simplicidad sobre los nuevos tiempos que vive la sociedad española centrados en la gran especulación inmobiliaria del Madrid de los años sesenta.

A fines de los años sesenta, nuestra novela ha emprendido ya con creces el experimentalismo y el realismo social da claras muestras de agotamiento, motivado por causas tanto literarias como extraliterarias. Dolores Medio no consigue salir de una novela de intención social, factura realista y procedimientos tradicionales; su registro sigue sin ninguna variación, las técnicas narrativas que utiliza en la elaboración de la ficción son una reiteración de los recursos tradicionales del género. A pesar de que sus últimas novelas se gestan en un periodo de experimentalismo for$\mathrm{mal}^{24}$, no atienden a ningún tipo de ruptura normativa ni a ningún efecto de artificiosidad: los procedimientos formales sirven mejor a sus propósitos.

Dolores Medio supo transmitir a sus lectores una reflexión personal sobre una sociedad determinada. El realismo social, que unificó temas y técnicas narrativas, fue también el cauce de una sensibilidad literaria, política e ideológica. La autora asturiana cumplió, junto a otros autores del movimiento, con el objetivo común; supo mostrar la realidad social con ánimo testimonial y de denuncia y contribuyó, por tanto, a la difusión de una determinada sensibilidad cultural.

24 En Farsa de verano (Madrid, Colección Austral, Espasa-Calpe, 1973) vuelve al personaje colectivo y en El fabuloso imperio de Juan sin Tierra (Barcelona, Plaza\&Janés, 1981), su última novela, a pesar de ensayar la alternancia de dos narradores - uno en primera persona y otro en tercera- y de incluir elementos fantásticos, vuelve a su mundo de siempre: la inmediata posguerra, la vida rural en Asturias, sus gentes, sus costumbres, su folklore. 